\title{
Evaluation on the Surface Modification of Recycled Fine Aggregates in Aqueous $\mathrm{H}_{2} \mathrm{SiF}_{6}$ Solution
}

\author{
Hwa-Sung Ryu' ${ }^{1)}$, Deuck-Mo Kim ${ }^{1)}$, Sang-Heon Shin ${ }^{1)}$, Seung-Min Lim²), and Won-Jun Park ${ }^{3), *} \mathbb{C}$
}

(Received September 11, 2017, Accepted February 6, 2018)

\begin{abstract}
Recycled aggregates (RAs) production techniques are essential for the material circulation society because RAs from demolished concrete waste can sustainably be reused as a concrete material. However, RAs can bring about several performance decreases when they are used for recycled aggregate concrete (RAC) because of the low qualities (i.e., high water-absorption rate and low density) caused by the attached hydrated cement paste on the RA surface. Therefore, both the production of high-quality RAs and the surface modification of RAs are significantly important for the extension of RAC utilization. This paper focuses on the surface modification of RFA to reduce the water absorption rate and increase density. Hydrofluorosilicic acid $\left(\mathrm{H}_{2} \mathrm{SiF}_{6}\right)$, which is one of the by-products in phosphoric acid manufacture, is used herein for the surface modification of the RFA. The physical properties and mechanical performance of mortar using RFA were evaluated after RFA modification. Consequently, the proposed method is effective in reducing water absorption rate and increasing density of RFA. The density of RFAs was slightly increased by $0.5-2.6 \%$ after modification. On the other hand, the water absorption rate decreased by $4-18 \%$ after modification. The compressive strengths of mortar at 28 days ages showed 18.1 MPa with modified RFA and 16.2 MPa with RFA.
\end{abstract}

Keywords: recycled aggregate, recycled fine aggregate, surface modification, hydrofluorosilicic acid, mortar.

\section{Introduction}

The current annual industrial waste in South Korea amounts to approximately 130 million tons, with more than $50 \%$ of that being construction waste such as excess concrete. Specifically, the amount of concrete waste comprises $70 \%$ of construction waste, which is approximately $40 \%$ of all industrial waste (46 million tons). More than $90 \%$ of concrete waste, or 40 million tons each year, is produced as recycled aggregates (RAs) after going through recycling processes. The reproduced RAs are mainly reused as subbase materials for roads, roadbed materials, and RAs for concrete (Noguchi et al. 2015; Shi et al. 2015). The quality of RAs produced from waste concrete via processes such as crushing, rubbing, smashing, and heating varies, and standards dependent on the physicochemical properties of the aggregates have been established for various countries as shown in Table 1 (AS 1996; DIN 4226-100 2002;

\footnotetext{
${ }^{1)}$ Hanyang Experiment and Consulting Co., $1271 \mathrm{Sa}$ 3-dong, Ansan 15588, Republic of Korea.

${ }^{2)}$ Inovative Durable Building and Infrastructure Research Center, Hanyang University, 1271 Sa 3-dong, Ansan 15588, Republic of Korea.

${ }^{3)}$ Department of Building System Engineering, Kangwon National University, Samcheok 25913, Republic of Korea. *Corresponding Author; E-mail: wjpark@kangwon.ac.kr Copyright (c) The Author(s) 2018. This article is an open access publication
}

Construction standard 2013; BS 812: Part 2 1994; JIS A 5021 2005; JIS A 5022 2007; JIS A 5023 2007; KS F 2573 1999; RILEM TC 121-DRG 1994; Spanish Minister of Public Works 2008).

The current standardized quality grades of RAs are divided according to aggregate absorption rate and specific gravity, and they are classified into structural concrete aggregates, non-structural concrete aggregates, roadbed materials, and so on, based on these grades as shown in Table 2 (Shi et al. 2015; Behera et al. 2014). In general, the reason that RAs are lower in quality than natural aggregates is because mortar adheres to the surface of RA (cement matrix). Low-quality RAs having a high absorption rate and low weight have limitations in terms of being reused for concrete (Behera et al. 2014; Choi et al. 2014; Ismail and Ramli 2014). Accordingly, most RAs are not used as concrete aggregates, but as roadbed and sub-base materials; however, this demand is gradually decreasing, while the demand for their use in concrete is continuously required. In addition, regarding RAs for roads and landfills, there are concerns about alkali extraction due to $\mathrm{Ca}(\mathrm{OH})_{2}$, which is contained in adhered mortar (cement matrix) on the surface of aggregates, and also other long-term problems of environmental concern (Shi et al. 2015; Chen et al. 2017; Tam et al. 2007).

For the sustainable recycling of resources, in order to recycle the waste concrete that is produced in large quantities, not only an active use, but also an eco-friendly use of RAs is important (Choi et al. 2014; Ismail and Ramli 2014; Chen et al. 2017; Tam et al. 2007; Kong et al. 2010). This 
Table 1 Acceptance criteria regarding RA

\begin{tabular}{|c|c|c|c|}
\hline Country or standard & RA type & Oven-dry density $\left(\mathrm{kg} / \mathrm{m}^{3}\right)$ & Absorption rate \\
\hline \multirow[t]{2}{*}{ Australia (AS1141.6.2) } & Class $1 \mathrm{~A}$ & $\geq 2100$ & $\leq 6 \%$ \\
\hline & Class 1B & $\geq 1800$ & $\leq 8 \%$ \\
\hline \multirow[t]{4}{*}{ Germany (DIN 4226-100) } & Type 1 & $\geq 2000$ & $\leq 10 \%$ \\
\hline & Type 2 & $\geq 2000$ & $\leq 15 \%$ \\
\hline & Type 3 & $\geq 1800$ & $\leq 20 \%$ \\
\hline & Type 4 & $\geq 1500$ & No limit \\
\hline Hong kong & - & $\geq 2000$ & $\leq 10 \%$ \\
\hline \multirow[t]{6}{*}{ Japan (JIS A 5021, 5022 and 5023) } & Coarse-class H & $\geq 2500$ & $\leq 3 \%$ \\
\hline & Fine-class $\mathrm{H}$ & $\geq 2500$ & $\leq 3.5 \%$ \\
\hline & Coarse-class M & $\geq 2300$ & $\leq 5 \%$ \\
\hline & Fine_-class $\mathrm{M}$ & $\geq 2200$ & $\leq 7 \%$ \\
\hline & Coarse-class L & No limit & $\leq 7 \%$ \\
\hline & Fine-class L & No limit & $\leq 13 \%$ \\
\hline \multirow[t]{2}{*}{ Korea (KS F 2573) } & Coarse & $\geq 2500$ & $\leq 3 \%$ \\
\hline & Fine & $\geq 2500$ & $\leq 3 \%$ \\
\hline \multirow[t]{3}{*}{ RILEM } & Type 1 & $\geq 1500$ & $\leq 20 \%$ \\
\hline & Type 2 & $\geq 2000$ & $\leq 10 \%$ \\
\hline & Type 3 & $\geq 2500$ & $\leq 3 \%$ \\
\hline Spain (EHE) & - & $\geq 2000$ & $\leq 5 \%$ \\
\hline
\end{tabular}

Table 2 Reference for categorizing concrete made with recycled coarse aggregate (RCA).

\begin{tabular}{c|c|c|c|c}
\hline \multirow{2}{*}{ Category } & \multicolumn{3}{|c|}{ Coarse aggregate } & Aggregates for concrete \\
\cline { 2 - 5 } & High quality & Medium quality & Low quality & Over 2.5 \\
\hline \hline Dried density $\left(\mathrm{t} / \mathrm{m}^{3}\right)$ & Over 2.5 & Over 2.3 & Below 7.0 & Below 3.0 \\
\hline Absorption rate (\%) & Below 3.0 & Below 5.0 & Below 2.0 & Below 7.0 \\
\hline Fine aggregate content (\%) & Below 1.0 & Below 1.5 & A 5023 5005 \\
\hline No. JIS & $\begin{array}{c}\text { A 5021 } \\
\text { aggregate or structural } \\
\text { concrete }\end{array}$ & $\begin{array}{c}\text { Concrete construction } \\
\text { elements not affected by } \\
\text { dry shrinkage }\end{array}$ & $\begin{array}{c}\text { Non-structural elements that } \\
\text { do not require durability } \\
\text { and strength }\end{array}$ & - \\
\hline
\end{tabular}

requires taking measures to simultaneously address the problems of low weight, high absorption rate, and alkali extraction that RAs currently have, and also requires the quality improvement of aggregates for use in concrete (Kong et al. 2010; Al-Bayati et al. 2016; Zhan et al. 2014).

There have been numerous studies reporting on surface modifications of RAs using carbonation and acid treatment, focusing on the fact that mortar adhered to the surface of RAs (cement matrix) contains profuse $\mathrm{Ca}(\mathrm{OH})_{2}$ (Chen et al. 2017; Tam et al. 2007; Kong et al. 2010; Al-Bayati et al. 2016; Zhan et al. 2014). The surface modification with carbonation is a method that uses accelerated carbonation, which reacts highly concentrated carbon dioxide with $\mathrm{Ca}(\mathrm{OH})_{2}$ of the adhered mortar on the aggregate surface under dry or wet environments (Zhan et al. 2014; Zhang et al. 2015). The mechanism of surface modification used for RAs by accelerated carbonation is described below.

$$
\begin{aligned}
& \mathrm{Ca}(\mathrm{OH})_{2}+\mathrm{CO}_{2} \rightarrow \mathrm{CaCO}_{3}+\mathrm{H}_{2} \mathrm{O} \\
& \mathrm{C}-\mathrm{S}-\mathrm{H}+\mathrm{CO}_{2} \rightarrow \mathrm{CaCO}_{3}+\mathrm{SiO}_{2} \cdot \mathrm{nH}_{2} \mathrm{O}
\end{aligned}
$$

On the other hands, the hydration products of cement in hardened paste can be dissolved in acid solution (Shi et al. 2015; Tam et al. 2007; Al-Bayati et al. 2016). Thus, acidic 
solution can be used to remove the adhered mortar effectively and enhance the quality of RA. Phosphoric acid, Sulfuric acid and hydrochloric acid are used in a typical acid treatment. The mechanisms of surface modification used for RAs by acid treatments are described below.

Reactions under $\mathrm{HCl}$ :

$$
\begin{aligned}
& \mathrm{CaO}+2 \mathrm{HCl} \rightarrow \mathrm{CaCl}_{2} \cdot \mathrm{H}_{2} \mathrm{O} \\
& \mathrm{Fe}_{2} \mathrm{O}_{3}+6 \mathrm{HCl} \rightarrow 2 \mathrm{FeCl}_{3} \cdot 3 \mathrm{H}_{2} \mathrm{O} \\
& \mathrm{Al}_{2} \mathrm{O}_{3}+6 \mathrm{HCl} \rightarrow 2 \mathrm{AlCl}_{3} \cdot 3 \mathrm{H}_{2} \mathrm{O}
\end{aligned}
$$

Reactions under $\mathrm{H}_{2} \mathrm{SO}_{4}$ :

$$
\begin{aligned}
& \mathrm{CaO}+\mathrm{H}_{2} \mathrm{SO}_{4} \rightarrow \mathrm{CaSO}_{4} \cdot \mathrm{H}_{2} \mathrm{O} \\
& \mathrm{Al}_{2} \mathrm{O}_{3}+3 \mathrm{H}_{2} \mathrm{SO}_{4} \rightarrow \mathrm{Al}_{2}\left(\mathrm{SO}_{4}\right)_{3} \cdot 3 \mathrm{H}_{2} \mathrm{O} \\
& \mathrm{Fe}_{2} \mathrm{O}_{3}+3 \mathrm{H}_{2} \mathrm{SO}_{4} \rightarrow \mathrm{Fe}_{2}\left(\mathrm{SO}_{4}\right)_{3} \cdot 3 \mathrm{H}_{2} \mathrm{O}
\end{aligned}
$$

Reactions under $\mathrm{H}_{3} \mathrm{PO}_{4}$ :

$$
\begin{aligned}
& 2 \mathrm{CaO}+\mathrm{H}_{3} \mathrm{PO}_{4} \rightarrow 2 \mathrm{Ca}^{2+}+\mathrm{H}^{+}+\mathrm{PO}_{4}^{3-}+2 \mathrm{OH}^{-} \\
& \mathrm{Al}_{2} \mathrm{O}_{3}+2 \mathrm{H}_{3} \mathrm{PO}_{4} \rightarrow 2 \mathrm{Al}^{3+}+3 \mathrm{H}^{+}+2 \mathrm{PO}_{4}^{3-}+3 \mathrm{OH}^{-}
\end{aligned}
$$

$$
\mathrm{Fe}_{2} \mathrm{O}_{3}+2 \mathrm{H}_{3} \mathrm{PO}_{4} \rightarrow 2 \mathrm{Fe}^{3+}+3 \mathrm{H}^{+}+2 \mathrm{PO}_{4}^{3-}+3 \mathrm{OH}^{-}
$$

In the "mechanical" first processing stage, RAs are produced and then subjected to the "chemical" second processing stage, in which carbonation and acid treatment are applied. Ultimately, both methods improve the physical properties of RAs. $\mathrm{Ca}(\mathrm{OH})_{2}$ within the adhered mortar is converted to $\mathrm{CaCO}_{3}$ by carbonation, and the porosity of the adhered mortar decreases, leading to an increase in the specific gravity of aggregates and a decrease in its absorption rate (Ryou and Lee 2014; Ondova and Sicakova 2016). The acid treatment results in an increased specific gravity of the aggregates and a decreased absorption rate through partially removing the adhered mortar and neutralizing the hydroxide $\left(\mathrm{OH}^{-}\right)$ions simultaneously. However, carbonation is associated with problems such as high costs of equipment, limited processed amount of aggregates per unit time, and difficult retrieval of unreacted carbon dioxide (Al-Bayati et al. 2016; Zhan et al. 2014; Zhang et al. 2015). Furthermore, for acid treatment, there are issues with high processing costs, secondary contaminated water, and contaminated water (Shi et al. 2015; Chen et al. 2017; Tam et al. 2007; Kong et al. 2010; Al-Bayati et al. 2016). Thus, a new processing method that can both achieve surface modification of RAs and improve the issues associated with existing methods is required.

This study focused on achieving efficient surface modification of RAs through acid treatment. In order to overcome the problems of high costs and secondary contaminated water generation, we applied strongly acidic hydrofluorosilicic acid $\left(\mathrm{H}_{2} \mathrm{SiF}_{6}\right)$ as an industrial by-product that is usually generated in processing and production stages of phosphogypsum or phosphatic fertilizer (Yang et al. 2005; Kim et al. 2004). The uses of $\mathrm{H}_{2} \mathrm{SiF}_{6}$ are various such as metal refinement, soil hardening agent, surface treatment agent, sterilizer and water system purification. In this research, for RFAs, we evaluated the decrease in absorption rate, increase in specific gravity, and reduction in $\mathrm{pH}$, in order to develop a method to achieve surface modification of RAs using $\mathrm{H}_{2} \mathrm{SiF}_{6}$. In addition, we evaluated the physical properties of mortar with modified RFAs using a physicochemical analysis, through which we were able to verify the usefulness of the RFAs, surface-modified by the method proposed in this study, as concrete aggregates.

\section{Experimental Procedure}

\subsection{Materials}

In the experiments, $\mathrm{H}_{2} \mathrm{SiF}_{6}$ of $\mathrm{pH} 1.0$ (10\% solution) was used as acid treatment for surface modification of RFAs. And both natural fine aggregate (NFA) and RFAs were used, and the basic physical properties of the fine aggregates are shown in Table 3 . Three types of recycled aggregates (RFA 1, 2 and 3) were used in this study. As shown in Tables 1 and 2, RFA-2 and 3 are considered low-quality recycled aggregates used as roadbed. RFA-1 can be used as aggregate for mortar or concrete because it has higher physical quality than relatively different recycled aggregate. The chemical composition of cement is shown in Table 4.

\subsection{Experiment Outline}

In order to evaluate the surface modification of RFAs by the $\mathrm{H}_{2} \mathrm{SiF}_{6}$ proposed for use in this research, we measured the change in $\mathrm{pH}$, specific gravity, and absorption rate of the fine aggregates. To evaluate the physical-mechanical properties of the mortar before and after surface modification of the fine aggregates, the setting time, flow, and compressive and flexural strengths were measured. Additionally, we performed Scanning Electron Microscope (SEM), Thermogravimetric Differential Thermal Analysis (TG/DTA), Mercury Intrusion Porosimetry (MIP), and X-ray diffractometer (XRD) as chemical analyses. The mortar specimens were created by using natural, recycled, and modified-RFAs. Table 5 shows the test items and methods for RFAs presoaking in water and acid. And Table 6 shows the test items and method for mortar and their related standards.

\subsubsection{Specific Gravity and Absorption Rate of Fine Aggregates}

As shown in Tables 3 and 5, we measured the specific gravity and absorption rates of natural and RFAs that were used in our experiments and also the air-dried specific gravity and over-dry one for the specific gravity of aggregates.

\subsection{2 $\mathrm{pH}$ Measurement}

We measured the respective changes in $\mathrm{pH}$ by $\mathrm{Ca}(\mathrm{OH})_{2}$ within the cement matrices adhered to the RFAs and by 
Table 3 Physical properties of fine aggregates.

\begin{tabular}{c|c|c}
\hline Aggregate type & Density $\left(\mathrm{t} / \mathrm{m}^{3}\right)$ & Water absorption rate $(\%)$ \\
\hline \hline NFA & 2.52 & 0.54 \\
\hline RFA-1 & 2.34 & 5.12 \\
\hline RFA-2 & 2.19 & 8.37 \\
\hline RFA-3 & 2.27 & 7.64 \\
\hline
\end{tabular}

Table 4 Chemical composition of cement.

\begin{tabular}{c|c|c|c|c|c|c|c|}
\hline \multicolumn{9}{c|}{ Chemical composition (\%) } & \multicolumn{2}{c}{ Specific gravity } \\
\hline $\mathrm{SiO}_{2}$ & $\mathrm{Al}_{2} \mathrm{O}_{3}$ & $\mathrm{Fe}_{2} \mathrm{O}_{3}$ & $\mathrm{CaO}$ & $\mathrm{MgO}$ & $\mathrm{SO}_{3}$ & LOI & \\
\hline 21.95 & 6.59 & 2.81 & 60.12 & 3.32 & 2.11 & 2.58 & 3.15 \\
\hline
\end{tabular}

LOI loss on ignition.

Table 5 Test items and methods (RFAs) (ASTM International 2012).

\begin{tabular}{|c|c|c|c|c|}
\hline Items & Fine aggregates & Conditions & Number of measurement & Standard \\
\hline $\begin{array}{l}\text { Specific gravity and } \\
\text { absorption rate }\end{array}$ & NFA, RFA & $\begin{array}{l}\text { Air-dried specific gravity, } \\
\text { over-dry specific gravity }\end{array}$ & More than twice each & ASTM C 128 \\
\hline \multirow[t]{3}{*}{$\mathrm{pH}$} & RFA & $\begin{array}{c}{[\text { Method-1] }} \\
\text { RFAs }(50 \mathrm{~g})+\text { distilled } \\
\text { water }(300 \mathrm{~g})\end{array}$ & More than 3 times each & - \\
\hline & RFA & $\begin{array}{c}\quad[\text { Method-2] } \\
\text { RFAs }(50 \mathrm{~g})+\text { distilled } \\
\text { water }(300 \mathrm{~g}) 1 \text { st stirring } \\
\rightarrow \mathrm{H}_{2} \mathrm{SiF}_{6} \text { input } \rightarrow 2 \text { nd } \\
\text { stirring }\end{array}$ & More than 3 times each & \\
\hline & RFA & $\begin{array}{c}\text { [Method-3] } \\
\text { RFAs }(50 \mathrm{~g})+\text { distilled } \\
\text { water }(300 \mathrm{~g})+\mathrm{H}_{2} \mathrm{SiF}_{6} \\
\text { stirring }\end{array}$ & More than 3 times each & \\
\hline
\end{tabular}

Table 6 Test items and methods (Mortar) (ASTM International 2006, 2012, 2013, 2013, 2014 ).

\begin{tabular}{c|c|c|c|c}
\hline Items & Fine aggregates & Conditions & Number of measurement & Standard \\
\hline \hline Setting time & NFA, RFA, Modified RFA & Initiation and termination & More than twice each & ASTM C 191 \\
\hline Flow & NFA, RFA, Modified RFA & - & More than twice each & ASTM C 230 \\
\hline $\begin{array}{c}\text { Compressive strength, } \\
\text { flexural strength }\end{array}$ & NFA, RFA, Modified RFA & Age of 3, 7, and 28 days & More than three times Each & ASTM C 109 \\
\hline
\end{tabular}

$\mathrm{H}_{2} \mathrm{SiF}_{6}$ in the state of aqueous solutions under three different conditions, as displayed in Table 5. First, RFAs and distilled water were combined with a weight ratio of 1:6 and measured the $\mathrm{pH}$ values for different stirring times of the solution $(0,1,3$, and $5 \mathrm{~min})$. Also, we conducted the first stirring of distilled water and RFAs for $5 \mathrm{~min}$, deposited 8, 10, and $12 \mathrm{~g}$ of $\mathrm{H}_{2} \mathrm{SiF}_{6}$ into three different solutions, and measured their $\mathrm{pH}$ values based on second stirring times of $0,1,3$, and 5 min. Lastly, we mixed RFAs and distilled water with a

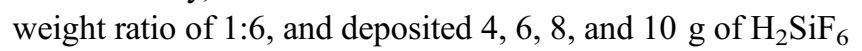
into four different solutions, and measured their $\mathrm{pH}$ values based on different stirring times if $0,1,3$, and $5 \mathrm{~min}$.

\subsubsection{Evaluation of Material Properties of Mortar}

Mortar specimens were produced using natural and RFAs. For the mortar specimen with modified-RFAs, the method having the best surface modification was used.

\section{Results and Analysis}

\section{$3.1 \mathrm{pH}$}

Table 7 displays the $\mathrm{pH}$ measurement results based on different stirring times of the distilled water and RFAs (Method-1 in Table 5). It was shown that the RFAs had a pH of about 10.51 when soaked in distilled water and the $\mathrm{pH}$ 
Table 7 Stirring times of distilled water and RFAs and changes in $\mathrm{pH}$.

\begin{tabular}{c|c|c|c|c}
\hline \multirow{2}{*}{\begin{tabular}{c} 
Number of tests \\
\cline { 2 - 5 }
\end{tabular}} & $0 \mathrm{~min}$ & $1 \mathrm{~min}$ & $3 \mathrm{~min}$ & $5 \mathrm{~min}$ \\
\hline \hline 1 & 10.67 & 11.26 & 11.43 & 11.51 \\
\hline 2 & 10.36 & 11.29 & 11.44 & 11.57 \\
\hline 3 & 10.60 & 11.30 & 11.32 & 11.53 \\
\hline 4 & 10.44 & 11.28 & 11.45 & 11.51 \\
\hline
\end{tabular}

Table 8 Changes in $\mathrm{pH}$ by stirring times with $\mathrm{H}_{2} \mathrm{SiF}_{6}$.

\begin{tabular}{c|c|c|c|c|c}
\hline \multirow{2}{*}{$\mathrm{H}_{2} \mathrm{SiF}_{6}$} & $\mathrm{pH}$ before stirring & \multicolumn{4}{|c}{$\mathrm{pH}$ by stirring time } \\
\cline { 3 - 6 } & & $0 \mathrm{~min}$ & $1 \mathrm{~min}$ & $3 \mathrm{~min}$ & $5 \mathrm{~min}$ \\
\hline \hline $8 \mathrm{~g}$ mixed & 11.53 & 4.39 & 5.85 & 9.84 & 10.32 \\
\hline $10 \mathrm{~g}$ mixed & 11.52 & 3.84 & 4.89 & 8.24 & 9.52 \\
\hline $12 \mathrm{~g}$ mixed & 11.51 & 3.63 & 4.17 & 6.58 & 8.64 \\
\hline
\end{tabular}

tended to increase depending on the stirring time of the solution. We also confirmed consistent alkali extraction due to the $\mathrm{Ca}(\mathrm{OH})_{2}$ in the adhered cement matrices.

Table 8 shows the results of the $\mathrm{pH}$ measurements based on the second stirring times after conducting the first stirring of distilled water and RFAs for 5 min and depositing $\mathrm{H}_{2} \mathrm{SiF}_{6}$ into the solutions (Method-2 in Table 5). For the solutions containing 8, 10, and $12 \mathrm{~g}$ of $\mathrm{H}_{2} \mathrm{SiF}_{6}$, the $\mathrm{pH}$ values measured immediately after the addition of $\mathrm{H}_{2} \mathrm{SiF}_{6}$ were less than 5.0, implying that the solutions were acidic. The solutions that had less than $10 \mathrm{~g}$ of $\mathrm{H}_{2} \mathrm{SiF}_{6}$ added after 3 min of stirring showed $\mathrm{pH}$ values of less than 10 , implying alkalescence. For a solution to have a $\mathrm{pH}$ range under 10 in up to

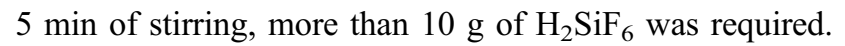

Meanwhile, the $\mathrm{pH}$ measurements after depositing RFAs into distilled water and adding $\mathrm{H}_{2} \mathrm{SiF}_{6}$ are shown in Table 9 (Method-3 in Table 5). When the properties of the solutions with $4,6,8$, and $10 \mathrm{~g}$ of $\mathrm{H}_{2} \mathrm{SiF}_{6}$ were evaluated, for the unextracted RFAs, the $\mathrm{pH}$ values of the solutions fell within the "acidic" range under 3.0; when each specimen was stirred, its $\mathrm{pH}$ tended to increase inversely proportional to the amount of $\mathrm{H}_{2} \mathrm{SiF}_{6}$ added.

\subsection{Specific Gravity and Absorption Rates of Fine Aggregates}

The results of testing the specific gravity and absorption rates of NFA and RFAs are shown in Table 10. The test results of the modified RFAs correspond to the case with $10 \mathrm{~g}$ of $\mathrm{H}_{2} \mathrm{SiF}_{6}$ added and $5 \mathrm{~min}$ of stirring in Table 9 (Method-3 in Table 5). The density of RFAs was slightly increased by $0.5-2.6 \%$ after modification. On the other hand, the water absorption rate decreased by $4-18 \%$ after modification. The decrease of the absorption rate of the aggregate due to the modification was found to be an increase of the aggregate density.

\subsection{Mortar Setting Times and Flows}

Three types of recycled aggregates (RFA 1, 2 and 3) were used in this study. RFA-2 and 3 are considered low-quality recycled aggregates used as roadbed materials because of their high water uptake after modification. However, it has confirmed the alkali leaching reduction effect and can be used as a more environmentally stable roadbed material. RFA-1 can be used as aggregate for mortar or concrete because it has higher physical quality than relatively different recycled aggregate. Therefore, RFA-1 and modified RFA-1 were used in the preparation of mortar specimens for the following experiments and analyzes.

Table 11 indicates the results of testing the flows and setting times of mortar using NFA, RFA-1, and modified RFA-1. In this case, the modified RFAs with $10 \mathrm{~g}^{\circ} \mathrm{H}_{2} \mathrm{SiF}_{6}$ added and 5 min of stirring in Table 9 was used for mortar.

The RFA had relatively smaller flows when compared to the NFA, and the flows of the modified RFA were found to

Table 9 Changes in $\mathrm{pH}$ pH by stirring time after mixing $\mathrm{H}_{2} \mathrm{SiF}_{6}$.

\begin{tabular}{c|c|c|c|c|c}
\hline \multirow{2}{*}{$\mathrm{H}_{2} \mathrm{SiF}_{6}$} & $\mathrm{pH}$ before stirring & \multicolumn{4}{|c}{$\mathrm{pH}$ by stirring time after mixing $\mathrm{H}_{2} \mathrm{SiF}_{6}$} \\
\cline { 3 - 6 } & & $0 \mathrm{~min}$ & $1 \mathrm{~min}$ & $3 \mathrm{~min}$ & $5 \mathrm{~min}$ \\
\hline \hline $4 \mathrm{~g}$ mixed & 10.64 & 3.80 & 9.15 & 9.78 & 11.04 \\
\hline $6 \mathrm{~g}$ mixed & 10.45 & 3.50 & 6.54 & 8.04 & 10.20 \\
\hline $8 \mathrm{~g}$ mixed & 10.36 & 3.30 & 4.01 & 7.85 & 9.80 \\
\hline $10 \mathrm{~g}$ mixed & 10.52 & 3.00 & 3.52 & 8.24 \\
\hline
\end{tabular}


Table 10 Changes in the specific gravity and absorption rate of fine aggregates.

\begin{tabular}{c|c|c|c|r}
\hline \multirow{2}{*}{ Aggregate type } & \multicolumn{2}{|c|}{ Before } & \multicolumn{3}{c}{ After } \\
\cline { 2 - 5 } & Density $\left(\mathrm{t} / \mathrm{m}^{3}\right)$ & Water absorption rate (\%) & Density $\left(\mathrm{t} / \mathrm{m}^{3}\right)$ & Water absorption rate $(\%)$ \\
\hline \hline NFA & 2.52 & 0.54 & 2.51 & 0.55 \\
\hline RFA-1 & 2.34 & 5.12 & 2.39 & 4.88 \\
\hline RFA-2 & 2.19 & 8.37 & 2.20 & 6.84 \\
\hline RFA-3 & 2.27 & 7.64 & 2.33 & 6.58 \\
\hline
\end{tabular}

Table 11 Mortar setting times and flows.

\begin{tabular}{c|c|c|c}
\hline Used aggregate type of mortar & Flow (mm) & Initiation (min) & Termination (min) \\
\hline \hline NFA & 180 & 250 & 450 \\
\hline RFA & 130 & 200 & 400 \\
\hline Modified-RFA & 150 & 220 & 410 \\
\hline
\end{tabular}

be greater than those of the RFA (unmodified). Because of the high absorption rates of RFA, the values of their flows appeared to be relatively low, but on the other hand, there was a positive effect on the flows of the modified RFA. Even though there were relative differences among the mortar samples with different setting times, it was found that the initiation and termination times satisfied their prescribed ranges in all levels.

\subsection{Mechanical Properties of Mortar}

The results of the compressive strength test and flexural strength test of the mortar using each type of aggregates are shown in Figs. 1 and 2. The results show that the compressive strength of mortar with RFAs was lower than that of mortar with NFA, and the compressive strength of mortar with modified RFA was smaller than that of mortar with NFA, but greater than that of mortar with RFA. The improvement in compressive strength of the modified RFA appears to result from the enhancement of its specific gravity and reduction in its absorption rates. Because of the characteristics of fine aggregates, it is very difficult to control their moisture content in a surface-dry state, but even when taken into consideration, it can be seen that there is an evident relationship between the enhancement of material properties of RFA through surface modification and the compressive strength of mortar. In addition, after testing the flexural strength of mortar, the flexural strengths of mortar were in the same descending order as the compressive strengths (28 days ages): NFA (22.7 MPa), modified RFA (18.1 MPa), and RFA (16.2 MPa).

\subsection{Chemical Analysis}

Figure 3 shows the SEM results based on different mortar curing periods. CSH and ettringite were clearly observed in the NFA and RFA in the early age. $\mathrm{CH}, \mathrm{CSH}$, and ettringite were observed on the 28th day regardless of the fine aggregate type. When modified RFA was used, the hydration reaction proceeded relatively late, but the effect of porosity and compressive strength was better than that of RFA. The

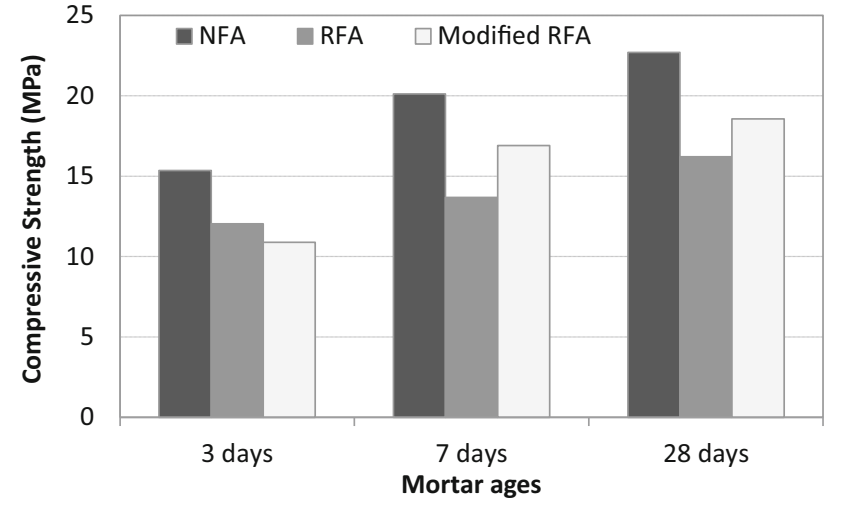

Fig. 1 Compressive strength of mortar.

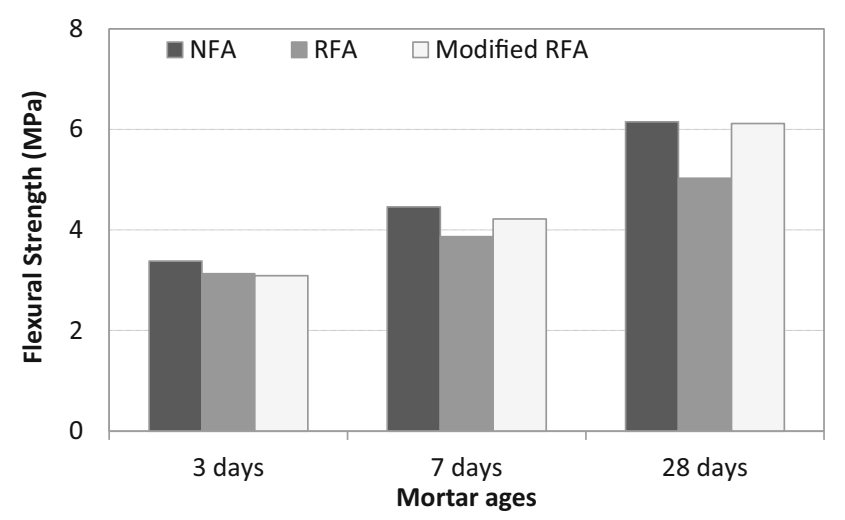

Fig. 2 Flexural strength of mortar.

effect of $\mathrm{CaF}_{2}, \mathrm{SiO}_{2}$ and residual $\mathrm{H}_{2} \mathrm{SiF}_{6}$ formed on the modified aggregate surface were affected. However, the decrease of the water absorption rate and the density of the aggregate increased the compressive strength of mortar. TGDTA regarding three different types of mortar at the ages of 3 and 28 days, and the contents of $\mathrm{Ca}(\mathrm{OH})_{2}$ and $\mathrm{CaCO}_{3}$ are shown in Table 12.

In addition, Fig. 4 represents the result of TG/DTA for the mortar at the age of 28 days. There were changes in weight 


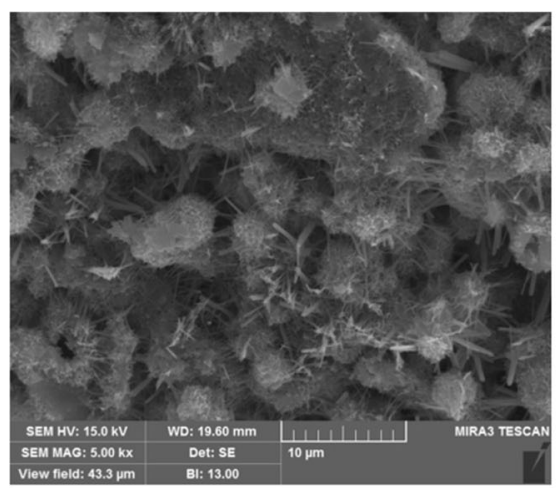

3 days

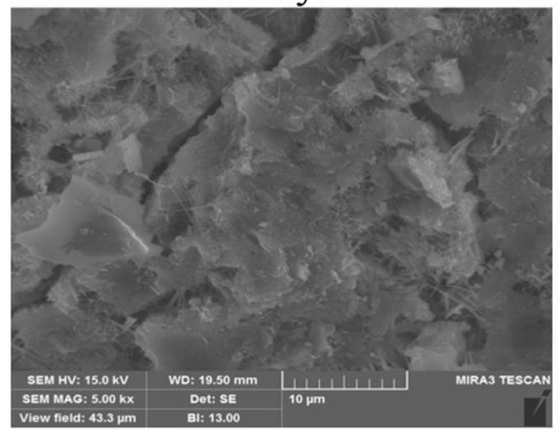

28 days

(a)

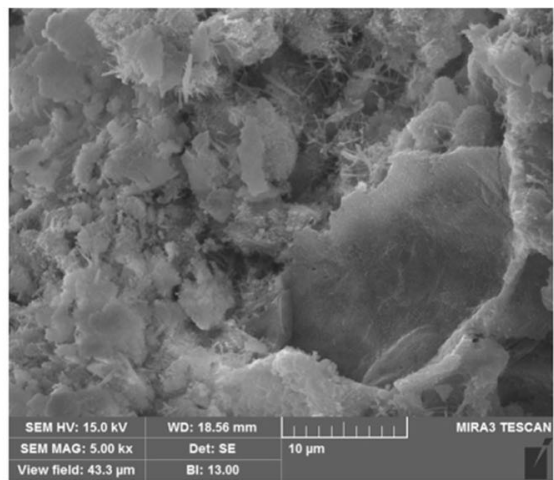

3 days

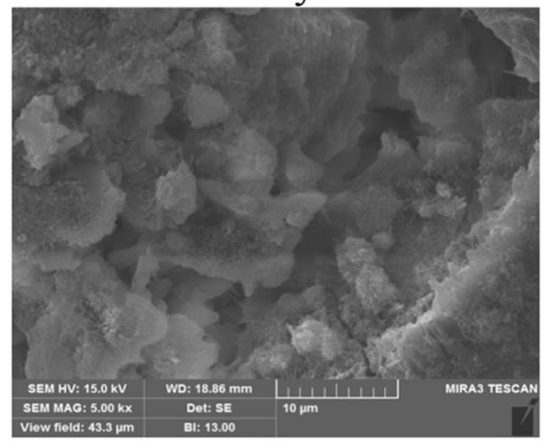

28 days

(b)

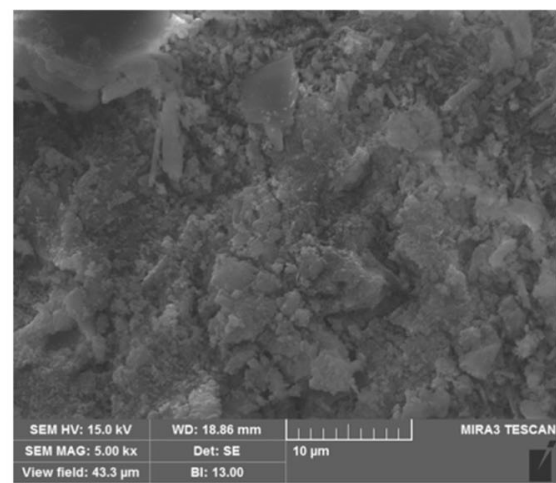

3 days

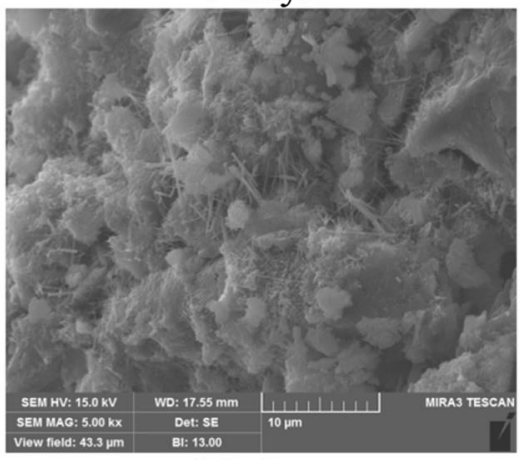

28 days

(c)

Fig. 3 SEM analysis based on mortar curing ( $\times 5000)$. a NFA, b RFA, and c modified RFA.

Table 12 Analysis of contents of $\mathrm{Ca}(\mathrm{OH})_{2}$ and $\mathrm{CaCO}_{3}$ by the age of mortar.

\begin{tabular}{c|c|c}
\hline Fine aggregates & $\mathrm{Ca}(\mathrm{OH})_{2}$ content $(\%)$ & $\mathrm{CaCO}_{3}$ content $(\%)$ \\
\hline \hline NFA (3 days) & 2.96 & 4.54 \\
\hline NFA (28 days) & 3.12 & 5.56 \\
\hline RFA (3 days) & 2.71 & 4.33 \\
\hline RFA (28 days) & 2.42 & 3.65 \\
\hline Modified RFA (3 days) & 2.18 & 5.54 \\
\hline Modified RFA (28 days) & 2.22 & 2.54 \\
\hline
\end{tabular}

for all specimens during the pyrolysis of $\mathrm{Ca}(\mathrm{OH})_{2}$ and $\mathrm{CaCO}_{3}$, and based on this result, the existence of $\mathrm{Ca}(\mathrm{OH})_{2}$ and $\mathrm{CaCO}_{3}$ was verified within the analyzed specimens. At up to $100{ }^{\circ} \mathrm{C}$ on DTA, the physically bonded water within the matrices evaporated, and there was physical dehydration of $\mathrm{C}_{3} \mathrm{~A}$ ettringite between 140 and $180{ }^{\circ} \mathrm{C}$, ettringite and aluminate-based hydrates between 270 and $330{ }^{\circ} \mathrm{C}$, and aluminate-based hydrates at around $570{ }^{\circ} \mathrm{C}$. In the case of mortar with RFA and modified RFA, their $\mathrm{Ca}(\mathrm{OH})_{2}$ contents were lower than that of mortar with NFA, and the $\mathrm{CaCO}_{3}$ contents of mortar with NFA and modified RFA, respectively, were measured lower than that of mortar with RFAs. As a result, the modification of RFA by $\mathrm{H}_{2} \mathrm{SiF}_{6}$ appeared to be effective.
The mortar porosity rate distribution dependent on mortar age is displayed in Fig. 5. The porosity at 3 days of age showed $20.025,20.295$, and $19.428 \%$ of NFA mortar, RFA mortar and modified RFA mortar respectively. On the other hand, the porosity at 28 days of age showed 16.950, 15.991, and $15.903 \%$ of NFA mortar, RFA mortar and modified RFA mortar respectively. The all mortar showed similar porosity. The smaller the pore size, the higher the distribution in NFA mortar. Modified RFA mortar showed a distribution of pores similar to NFA mortar than RFA mortar.

An XRD compound analysis was conducted on the test bodies of NFA, RFA, and modified RFA, and the results from day 3 and day 28 are shown in Fig. 6. Modified RFA mortar showed different compound composition compared 


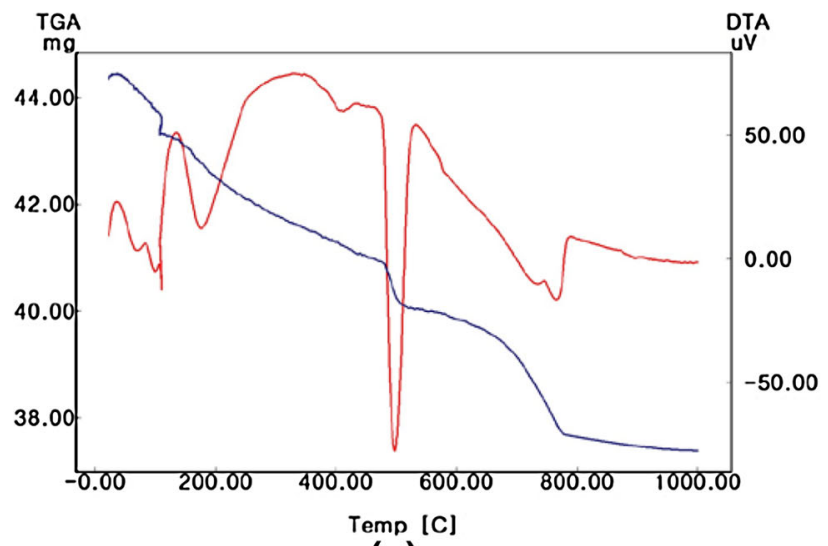

(a)
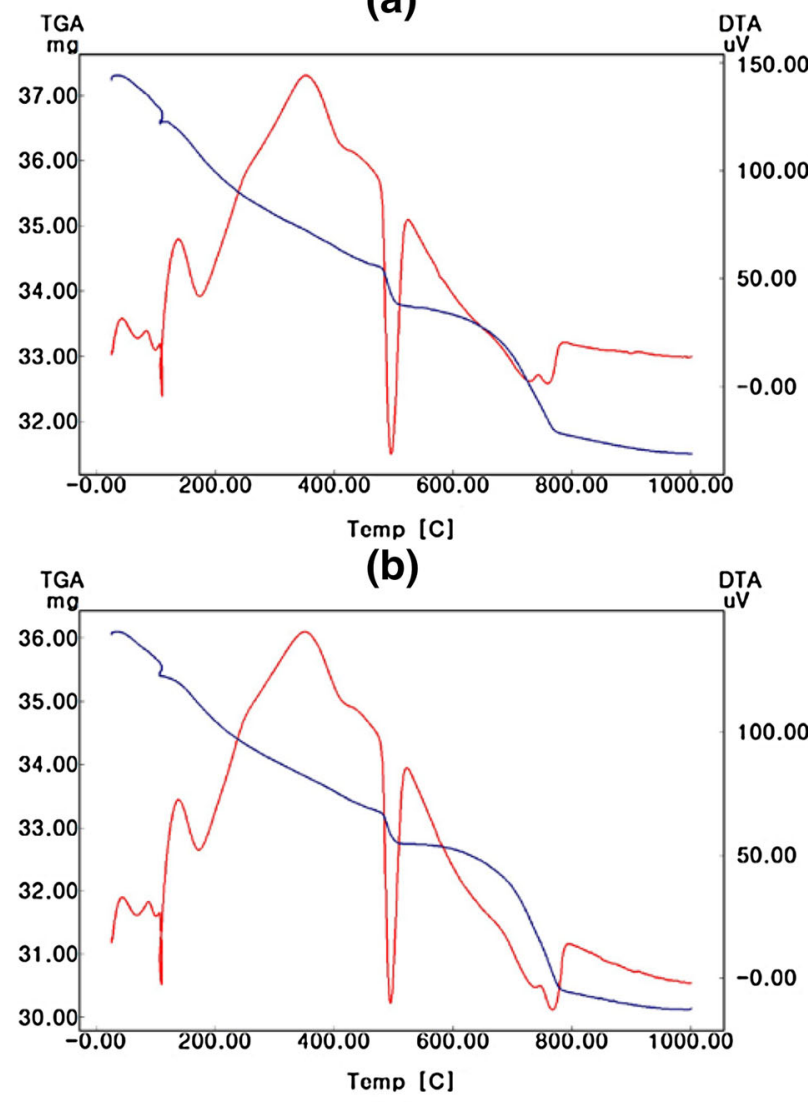

(c)

Fig. 4 Mortar TG/DTA (28 days). a mortar using NFA (28 days), b mortar using RFA (28 days), and $\mathbf{c}$ mortar using Modified RFA (28 days).

to RFA mortar. For the mortar on day 3, the early stage amount of $\mathrm{Ca}(\mathrm{OH})_{2}$ was relatively higher for mortar with RFA than for mortar with modified RFA. This is considered to result from the increase in the hardened cement paste attached to the surface of the RFA resulting from $\mathrm{Ca}(\mathrm{OH})_{2}$. Meanwhile, a relatively higher $\mathrm{CSH}$ generation was verified for mortar with modified RFA. For the mortar on day 28 with modified RFA, the amount of CSH generation was found to be increasing, which was considered to result from the supply of $\mathrm{Si}$ ions in the $\mathrm{H}_{2} \mathrm{SiF}_{6}$.

To investigate the RA surface modification method proposed in this paper, the absorption rates and specific gravity of RFA before and after treating with $\mathrm{H}_{2} \mathrm{SiF}_{6}$ were measured. Additionally, a physicochemical property evaluation and chemical analysis of mortar with modified RFA were conducted. The results verified the surface modification effect and the presence of changes in the physical properties of the RFA owing to the $\mathrm{H}_{2} \mathrm{SiF}_{6}$ in each experiment. The values of various mechanical properties of the modified RFA mortar were also found to be relatively high. The RFA surface modification method proposed in this study is based on the chemical reaction mechanism between $\mathrm{H}_{2} \mathrm{SiF}_{6}$ and abundant $\mathrm{Ca}(\mathrm{OH})_{2}$ contained in the hardened cement paste in the aqueous solution state as below.

Reactions under $\mathrm{H}_{2} \mathrm{SiF}_{6}$

$$
\begin{aligned}
\mathrm{H}_{2} \mathrm{SiF}_{6}+3 \mathrm{Ca}(\mathrm{OH})_{2} \rightarrow & 2 \mathrm{H}^{+}+\mathrm{Si}^{2+}+6 \mathrm{~F}+3 \mathrm{Ca}^{2+} \\
& +6 \mathrm{OH}^{-}
\end{aligned}
$$

$$
\begin{aligned}
& 2 \mathrm{H}^{+}+\mathrm{Si}^{2+}+6 \mathrm{~F}+3 \mathrm{Ca}^{2+}+6 \mathrm{OH}^{-} \\
& \rightarrow 3 \mathrm{CaF}_{2}+\mathrm{SiO}_{2}+4 \mathrm{H}_{2} \mathrm{O}
\end{aligned}
$$

The reaction between the $\mathrm{Ca}(\mathrm{OH})_{2}$ and $\mathrm{H}_{2} \mathrm{SiF}_{6}$ involves a chemical reaction that produces inorganic fine powders of $\mathrm{CaF}_{2}$ and $\mathrm{SiO}_{2}$. Wastewater is generated in recycled aggregate processing using the proposed method. Removal of fluoride from wastewater may be worse than acid wastewater. However, the fluoride in the wastewater is precipitated as an insoluble $\mathrm{CaF}_{2}$ form as described in the paper. During the wet process, $\mathrm{CaF}_{2}$ precipitate can be collected and disposed of separately.

On the other hand, it is thought that this reaction progresses gradually from the surface of the hardened cement paste attached to the RFA towards the inside, causing the cement matrix to become denser. The decrease in the absorption rate and the consequent increase in specific gravity are considered to be the filling effect of the surface porosity due to the densification of the matrix inside the hardened cement paste. A decreased aggregate absorption rate and an increased specific gravity were revealed as increased mortar compression strength compared to before the modification as the compressive strengths (28 days ages): NFA (22.7 MPa), modified RFA (18.1 MPa), and RFA (16.2 MPa). Therefore, it has been confirmed that the acid treatment of the RFA and $\mathrm{H}_{2} \mathrm{SiF}_{6}$ in aqueous solution, as proposed in this study, shows a surface modification effect similar to that of conventional carbonation treatment and acid treatment.

\section{Conclusions}

In this study, RFAs with high absorption rates and low specific gravities were wet-reacted with $\mathrm{H}_{2} \mathrm{SiF}_{6}$ having relative strong acidity, and various physical properties of the RFAs and mortar using the byproduct were confirmed. The results of this study are summarized as follows. 


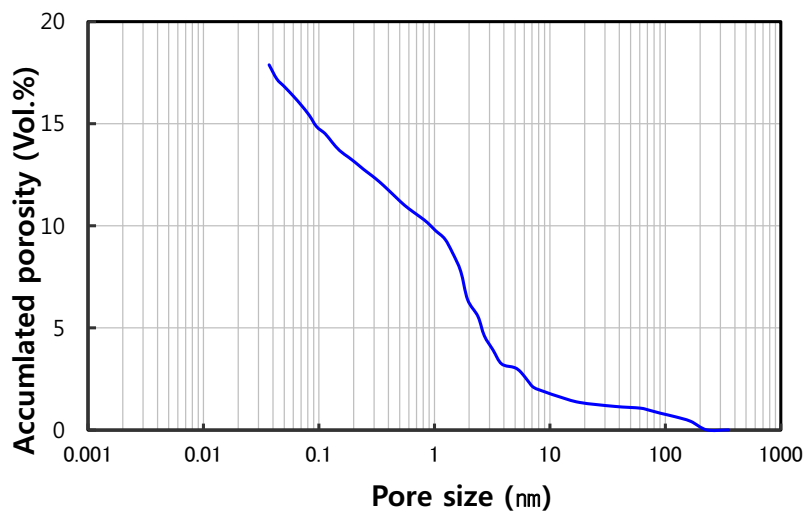

(a-1) Mortar using NFA (3 days)

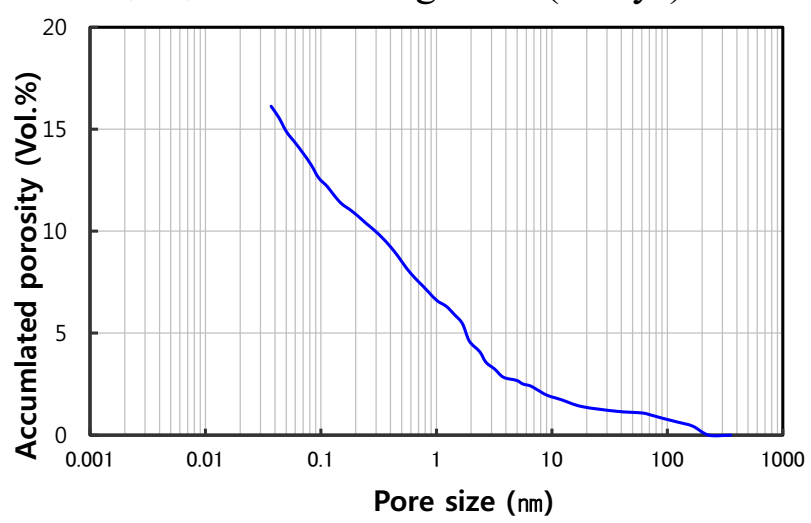

(b-1) Mortar using RFA (3 days)

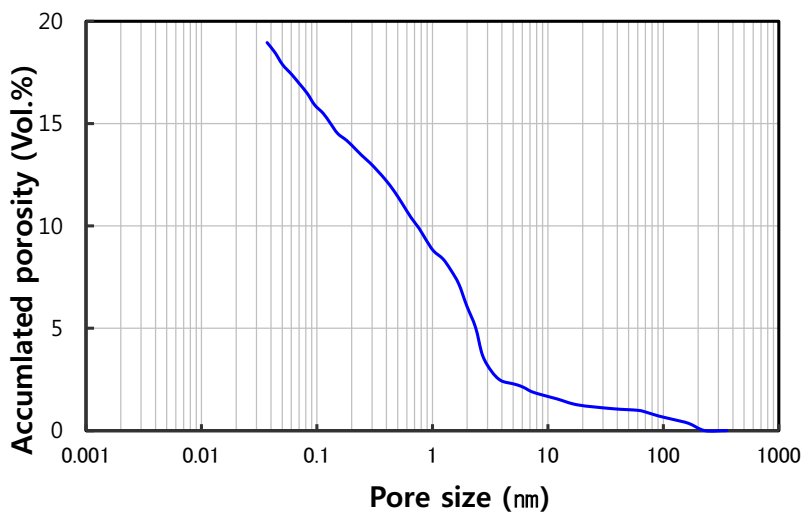

(c-1) Mortar using modified RFA (3 days)

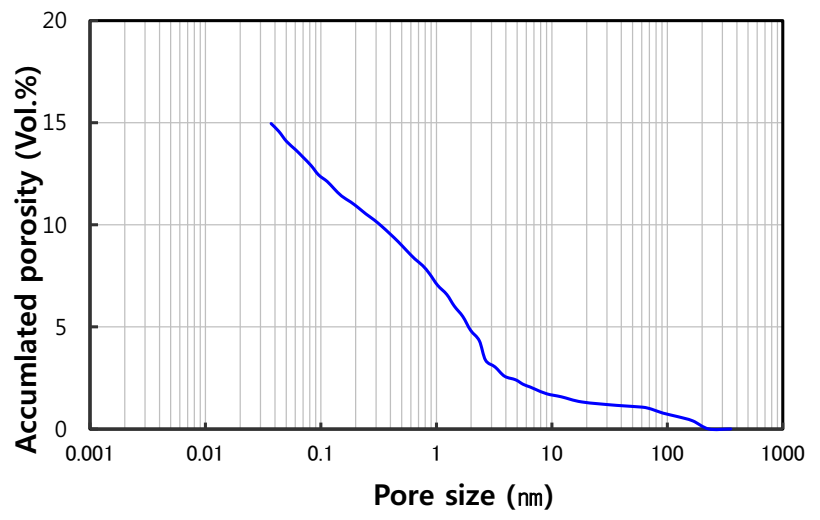

(a-2) Mortar using NFA (28 days)

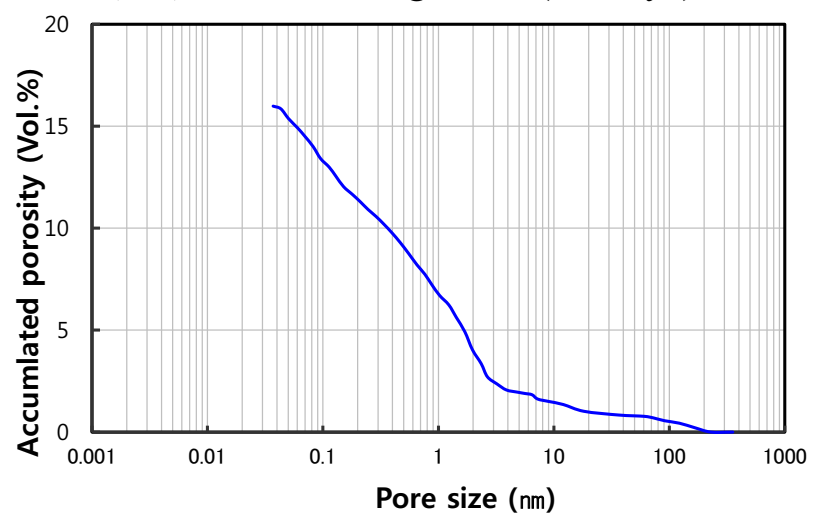

(b-2) Mortar using RFA (28 days)

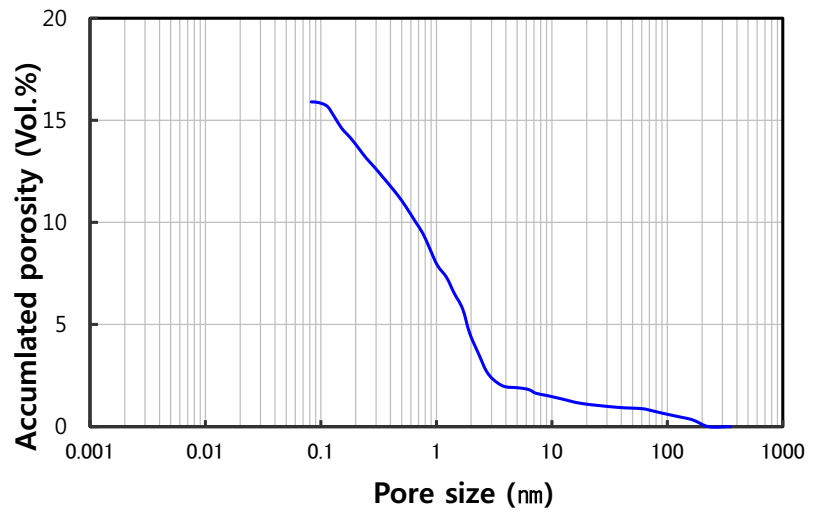

(c-2) Mortar using modified RFA (28 days)

Fig. 5 Mortar MIP.

1. When large amounts of $\mathrm{Ca}(\mathrm{OH})_{2}$ from hardened cement paste were attached to the surface of the RFAs and mixed with distilled water, alkaline ions are continuously eluted, resulting in $\mathrm{pH}$ values exceeding 11.5. When low quality RFAs were chemically treated in an aqueous solution containing $\mathrm{H}_{2} \mathrm{SiF}_{6}$, the absorption rate decreased and the specific gravity increased.

2. The proposed surface modification method is considered to result from the chemical reaction occurring on the RFA surface between $\mathrm{H}_{2} \mathrm{SiF}_{6}$ and $\mathrm{Ca}(\mathrm{OH})_{2}$, which is contained in abundance in the hardened cement paste attached to the surface of the RFA. Because of the production of $\mathrm{CaF}_{2}$ and $\mathrm{SiO} 2$ on the surface of the RFA as the result of the reaction with $\mathrm{H}_{2} \mathrm{SiF}_{6}$, an improvement in aggregate specific gravity and absorption rate was found to occur, and mortar test results confirmed enhanced strength.

3. By surface modification, mortar by using modified RFA showed improvements of mechanical properties in both compressive strength and flexural strength relatively tin comparison with mortar by using RFA.

4. Therefore, it was confirmed that the proposed RFA surface treatment method using $\mathrm{H}_{2} \mathrm{SiF}_{6}$, which is an industrial byproduct, is effective in improving the physical properties (high water absorption rate and low density) of RFA. 


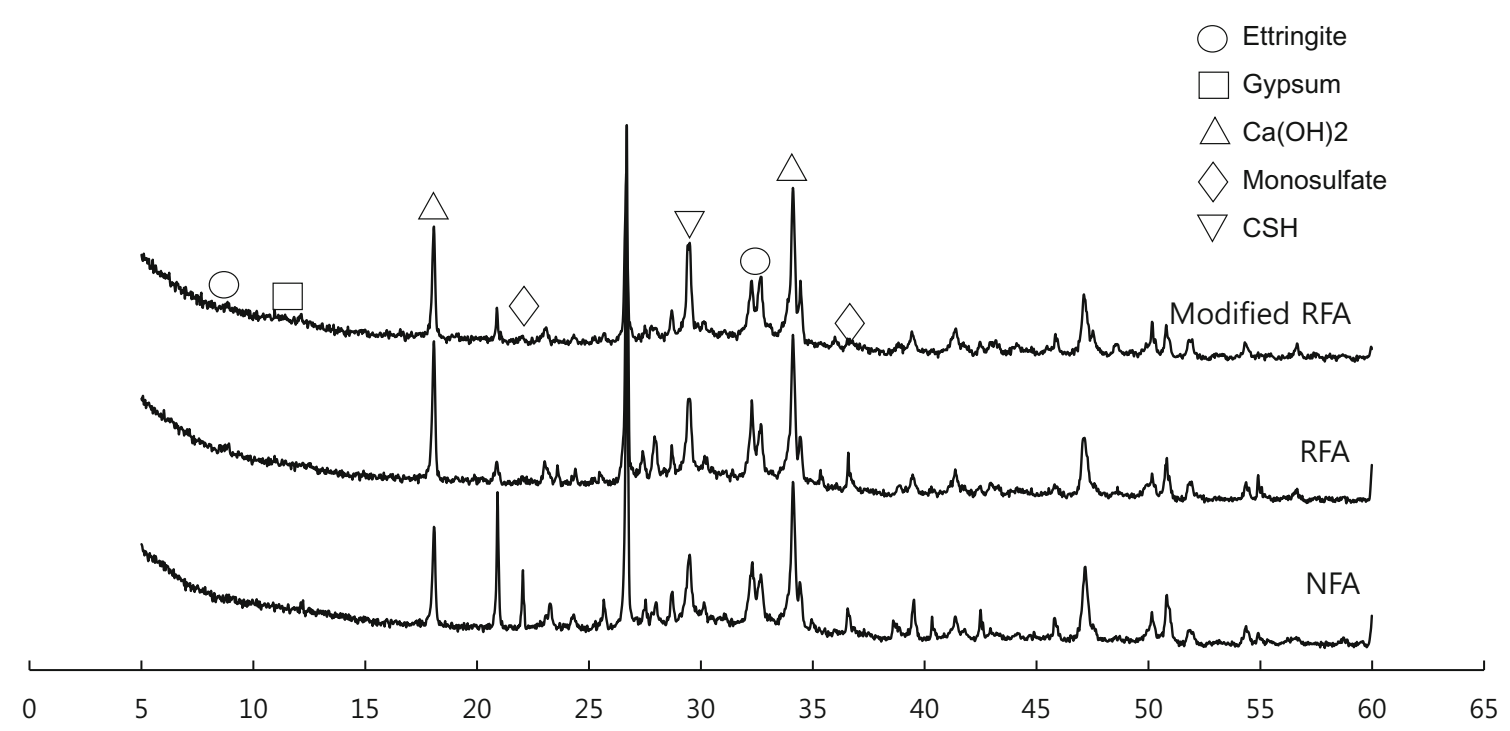

(a) 3 days

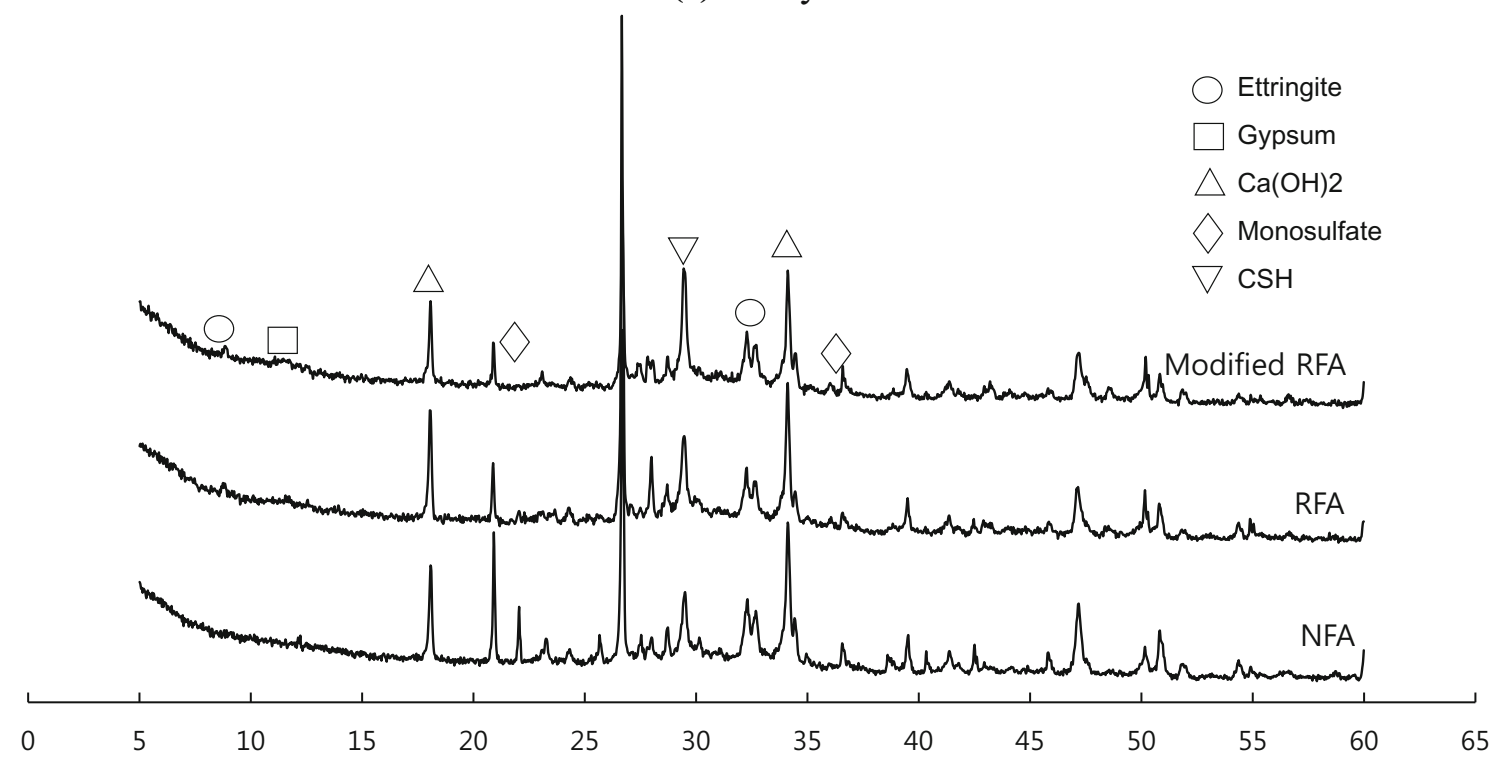

(b) 28 days

Fig. 6 XRD.

\section{Acknowledgements}

This research was supported by 2015 Research Grant from Kangwon National University, a research grant from Technology Advancement Research Program (TARP) funded by Ministry of Land, Infrastructure and Transport of Korean Government (15CTAP-C097331-01), and by the National Research Foundation of Korea (NRF) grant funded by the Korea government (No.NRF-2015R1D1A1A09059522).

\section{Open Access}

This article is distributed under the terms of the Creative Commons Attribution 4.0 International License (http:// creativecommons.org/licenses/by/4.0/), which permits un restricted use, distribution, and reproduction in any medium, provided you give appropriate credit to the original author(s) and the source, provide a link to the Creative Commons license, and indicate if changes were made.

\section{References}

Al-Bayati, H. K. A., Das, P. K., Tighe, S. L., \& Baaj, H. (2016). Evaluation of various treatment methods for enhancing the physical and morphological properties of coarse recycled concrete aggregate. Construction and Building Materials, 112, 284-298.

AS. (1996). Particle density and water absorption of aggregates (AS 1141.6.2-1996). Sydney: Australian Standard.

ASTM International. (2006). Standard test method for time of setting of hydraulic cement by vicat needle; ASTM C 191. West Conshohocken: ASTM International. 
ASTM International. (2012). Standard test method for density, relative density (specific gravity), and absorption of fine aggregate; ASTM C128-12. West Conshohocken: ASTM International.

ASTM International. (2013a). Standard test method for flow of hydraulic cement mortar; ASTM C1437-13. West Conshohocken: ASTM International.

ASTM International. (2013b). Standard test method for compressive strength of hydraulic cement mortars (using 2-in. or [50 mm] Cube Specimens); ASTM C109 M-13. West Conshohocken: ASTM International.

ASTM International. (2014). Standard specification for flow table for use in tests of hydraulic cement; ASTM C230/ 230 M-14. West Conshohocken: ASTM International.

Behera, M., Bhattacharyya, S. K., Minocha, A. K., Deoliya, R., \& Maiti, S. (2014). Recycled aggregate from C\&D waste \& its use in concrete-a breakthrough towards sustainability in construction sector: A review. Construction and Building Materials, 68, 501-516.

BS 812: Part 2. (1994). Testing aggregates. Method for qualitative and quantitative petrographic examination of aggregates. London: BSI.

Chen, P., Wang, J., Wang, L., Xu, Y., Qian, X., \& Ma, H. (2017). Producing vaterite by $\mathrm{CO} 2$ sequestration in the waste solution of chemical treatment of recycled concrete aggregates. Journal of Cleaner Production, 149, 735-742.

Choi, H. S., Kitagaki, R., \& Noguchi, T. (2014). Effective recycling of surface modification aggregate using microwave heating. Journal of Advanced Concrete Technology, $12,34-45$.

Construction standard CS3. (2013). Construction standard CS3: 2013-Aggregates for concrete, Civil engineering and development department of Hong Kong. http://www.cedd. gov.hk/eng/publications/standards_handbooks_cost/stan_cs3 2013.html

DIN 4226-100. (2002). Aggregates for mortar and concretePart 100: Recycled aggregates. Berlin: Deutsches Institut für Normung.

Ismail, S., \& Ramli, M. (2014). Influence of surface-treated coarse recycled concrete aggregate on compressive strength of concrete. International Journal of Civil, Environmental, Structural, Construction and Architectural Engineering, 8, 862-866.

JIS A 5021. (2005). Recycled aggregate for concrete-class $H$. Tokyo: Japan Concrete Institute.

JIS A 5022. (2007). Recycled concrete using recycled aggregate class $M$. Tokyo: Japan Concrete Institute.

JIS A 5023. (2007). Recycled concrete using recycled aggregate class L. Tokyo: Japan Concrete Institute.
Kim, J. O., Nam, J. H., Kim, D. S., \& Lee, B. K. (2004). Changes in hydration and watertightness of cement containing two-component fluosilicate salt based chemical admixture. Journal of the Korean Ceramic Society, 41, 749-755.

Kong, D. Y., Lei, T., Zheng, J. J., Ma, C. C., \& Jiang, J. (2010). Effect and mechanism of surface-coating pozzalanics materials around aggregate on properties and ITZ microstructure of recycled aggregate concrete. Construction and Building Materials, 24, 701-708.

KS F 2573. (1999). Recycled aggregate for concrete. Seoul: Korea Standard Association.

Noguchi, T., Park, W. J., \& Kitagaki, R. (2015). Risk evaluation for recycled aggregate according to deleterious impurity content considering deconstruction scenarios and production methods. Resources, Conservation and Recycling, 104, 405-416.

Ondova, M., \& Sicakova, A. (2016). Evaluation of the influence of specific surface treatments of RBA on a set of properties of concrete. Materials, 9, 156.

RILEM TC 121-DRG. (1994). Specifications for concrete with recycled aggregates. Materials and Structures, 27, 557-559.

Ryou, J. S., \& Lee, Y. S. (2014). Characterization of recycled coarse aggregate (RCA) via a surface coating method. International Journal of Concrete Structures and Materials, 8, 165-172.

Shi, C., Li, Y., Zhang, J., Li, W., Chong, L., \& Xie, Z. (2015). Performance enhancement of recycled concrete aggregateA review. Journal of Cleaner Production, 12, 466-472.

Spanish Minister of Public Works. (2008). Instrucción de Hormigón Estructural EHE-08 (Spanish Structural Concrete Code).

Tam, V. W. Y., Tam, C. M., \& Le, K. N. (2007). Removal of cement mortar remains from recycled aggregate using presoaking approaches. Resources, Conservation and Recycling, 50, 82-101.

Yang, I. S., Yun, H. D., Kim, D. S., Khil, B. S., \& Han, S. G. (2005). Experimental study on engineering properties of concrete using fluosilicates based composite. Korea Concrete Institute Structure Journal, 17, 769-774.

Zhan, B., Poon, C. S., Liu, Q., Kou, S., \& Shi, C. (2014). Experimental study on $\mathrm{CO} 2$ curing for enhancement of recycled aggregate properties. Construction and Building Materials, 67, 3-7.

Zhang, J., Shi, C., Li, Y., Pan, X., Poon, C. S., \& Xie, Z. (2015). Performance enhancement of recycled concrete aggregates through carbonation. Journal of Materials in Civil Engineering. https://doi.org/10.1061/(ASCE)MT.1943-5533.0001296. 